1996

\title{
Communications needs assessment in Egypt: Final Report
}

Sahar Hegazi

Follow this and additional works at: https://knowledgecommons.popcouncil.org/departments_sbsr-rh

Part of the Demography, Population, and Ecology Commons, Health Communication Commons, and the International Public Health Commons How does access to this work benefit you? Let us know!

\section{Recommended Citation}

Hegazi, Sahar. 1996. "Communications needs assessment in Egypt: Final Report." Cairo: Population Council. 


\section{Communications Needs Assessment in Egypt}

Final Report

Sahar Hegazi

Cairo, March 1996 


\section{ACKNOWLEDGMENT}

This survey was completed during January of 1996 to gain a better understanding of the constituencies of the Asia and the Near East Operations Research and Technical Assistance Project (ANE OR/TA Project) of the Population Council. The ultimate objective is to communicate more effectively the findings generated from research conducted by the project and to enhance their utilization.

This survey was made possible through the generous time availed by the survey respondents. Their interesting comments, quotes and ideas were invaluable in assisting the ANE OR/TA project communication program to have a better understanding of its audiences' needs.

Thanks also go to the members of the newly born communication working group that emerged from this needs assessment. The members' enthusiasm and interest to work as a team towards achieving effective dissemination of research was most encouraging.

Special thanks are due to Ms. Nagwa Farag (UNICEF) and Dr. Fatma El Zanaty (DHS) for sharing their dissemination and communication plans and activities.

Finally, I would like to thank my colleagues at the Population Council / Cairo and Delhi office for their constructive comments and remarks. 


\section{TABLE OF CONTENTS}

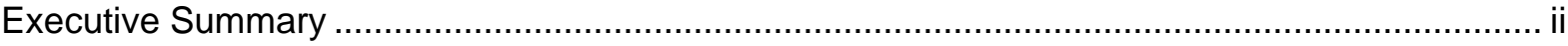

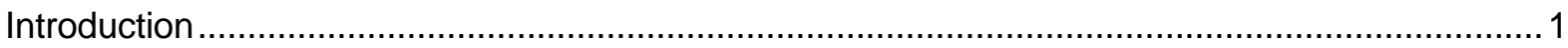

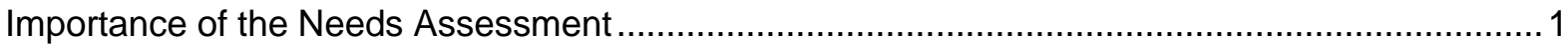

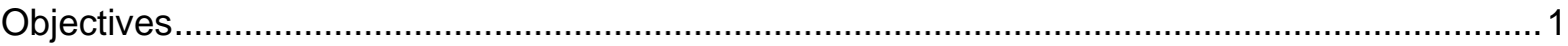

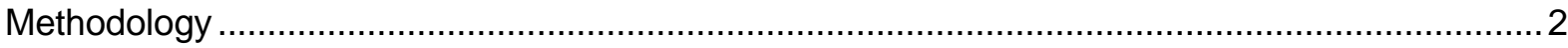

Findings

1. Dissemination of Operations Research: General Guidelines.................................... 3

2. ANE OR/TA Project Target Groups ........................................................................ 4

3. ANE OR/TA Project Audience Information Needs and Message Format ..................... 6

4. Channel Mix in Disseminating Findings of ANE OR/TA Project Research..................... 7

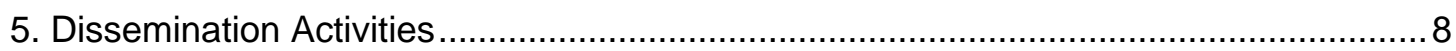

6. Assessment of the Dissemination Program of ANE OR/TA Project ............................... 9

7. Networking with National and International Organizations:......................................... 10 Communications Round-table Discussion

Lessons Learned from the Needs Assessment and Follow-Up Activities ..................................11

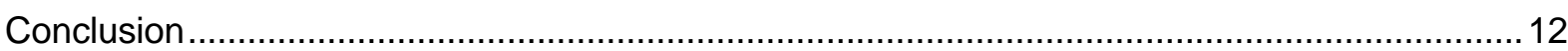

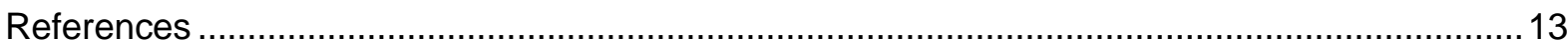

Appendices

A. List of interviewees and agencies contacted ................................................ 14

B. Minutes of the communications round-table discussion .......................................... 15 


\section{EXECUTIVE SUMMARY}

The recently approved dissemination strategy of the Population Council's ANE OR/TA Project aims to improve the communication process for diffusing study results, enhance their utilization and institutionalize the OR communications methods in each of the ANE OR/TA countries. One of the first steps in implementing this new strategy was to take a fresh look at the communications needs within each country. A communications needs assessment was conducted to carefully re-examine the range of target audiences, define the type of messages each responds to best, identify the most appropriate mix of media for transmitting those messages and consolidate linkages with other communications professionals working within related fields. This exercise has been conducted in Egypt between January and March 1996.

The methodology of this assessment was based on conducting a series of in-depth interviews with key informants from ANE OR/TA Project audiences and organized a round table discussion with communications professionals to review reactions to past communications activities in Egypt (both those of the ANE OR/TA Project and other research activities) and to explore the ways and means for improving the content, presentation and production of future communications products.

Findings revealed a broad sense of satisfaction with the ANE OR/TA dissemination activities among all of the project's constituencies in Egypt. The Research Summaries have been appreciated as an effective tool to disseminate research by senior officials (within the Egyptian Government and donor community) while program managers highly valued final reports and end of project seminars. Mid-level managers and clinicians found the production of Arabic language materials particularly helpful. There was a strong consensus that follow-up / small group meetings, after holding a large seminar where the final report is released, are most effective to ensure the utilization of research. It was mentioned that dissemination seminars provide an opportunity for an exchange of experiences about other programs. The Evaluation techniques used by other organizations were also useful to learn about.

An unexpected outcome of the Egyptian Communications Needs Assessment has been the formation of a nascent professional association of communications experts in the field of population. This group, convened to discuss operations research communications activities, saw a pressing need to increase opportunities to meet and discuss wide ranging issues concerning their field of work. The group decided to meet every quarter to enhance their professional development and facilitate the sharing of information.

This Needs Assessment will strengthen the basis for implementing forthcoming dissemination activities. The important lessons learned from this exercise will not only be useful to the dissemination program of the ANE OR/TA project, but also to other OR Projects and similar programs in other organizations' both within Egypt and in other countries. 


\section{INTRODUCTION}

During the first phase of the ANE OR/TA project (1990-1995) a dissemination strategy was developed to guide the communications activities and systematically address the objectives of communicating the studies findings to a diverse array of audiences within each country, regionally and internationally. Several activities were undertaken to create a coherent and unified framework for disseminating results and informing our audiences of recent project developments.

The evaluation of the project's first phase provided insight for exploring new avenues for dissemination. The objective is to extend the reach of the dissemination activities to a wider range of audiences by improving the focus of the messages and using the most suitable channels. The diversification of dissemination activities on the local as well as the regional level will enhance the utilization of research findings and will bring about a greater impact.

\section{IMPORTANCE OF THE NEEDS ASSESSMENT}

The needs assessment is an information gathering process for analyzing the strengths, weakness, and identifying the opportunities for improving the communication and dissemination activities. Information on the barriers to the dissemination process and the means to overcome these problems are one of the results of this exercise (Taylor et al, 1987; Katz, et al, 1993 and Maibach \& Parrott, 1995). Learning more about the different audiences is a prerequisite to developing a more effective program. This needs assessment also addresses the overall ANE OR/TA Project objective of institutionalizing the OR communications procedures in each country.

\section{OBJECTIVES}

The long term objective of the needs assessment is to enhance the utilization of research findings, to increase the acceptability, accessibility and the quality of family planning services.

The short term objectives are:

1. Refine the definition of the ANE OR/TA Project sub-target groups within the countries,

2. Assess audience knowledge and views of the existing dissemination activities of the ANE OR/TA Project and their strengths and weakness,

3. Identify the audience specific information needs related to operations research,

4. Classify channels mix catered to these needs, and suggest a message format for strategically targeting their presentation.

5. Develop a network with other national and international organizations. 


\section{METHODOLOGY}

In conducting the communications needs assessment three main techniques were utilized. One was a review of the dissemination activities of two agencies that regularly communicate results of research. This was implemented through interviews with key staff in these organizations. Second, in-depth interviews with a selection of our target audiences were conducted. Third, a participatory group discussion of selected communications specialists involved in population communications activities was held. This discussion served to establish a stronger network with the ANE OR/TA project collaborators.

\section{Review of Other Agencies Conducting Research}

It is important to know how other organizations have approached the dissemination of their research. This technique helped to reveal what others have done, what kind of materials and messages they produce, how successful they are, how they measure their effectiveness and what are the barriers they face. The survey also provided important information on some of the resources in implementing communication activities. These resources include editors, publishers, graphic artists...etc. Assessment of other cooperating agencies was also important in identifying possible means of mutual cooperation.

\section{In-depth Interviews of the ANE OR/TA Project Audience}

Six informants were selectively chosen for the in-depth interviews from the ANE OR/TA project's largest audiences in Egypt. The ANE OR/TA project target groups are classified into the following three categories: 1) decision and policy makers 2) service institutions (locally and regionally), and 3 ) donors and international foundations. The questionnaire addressed basic concerns about the knowledge of the ANE OR/TA project activities, their strengths and weaknesses and more effective tools for disseminations. The survey provided indicators of audience feedback on some of the forthcoming dissemination activities such as using electronic medium in dissemination. It also probed into the information needs of our target groups and the relevant messages to address these needs. In addition, it revealed some information on effective channels for different groups and related activities to dissemination of research. (For a complete list of interviewees and agencies contacted, please refer to Appendix A).

\section{Expert Group Discussion}

The communication officer of the ANE OR/TA Project initiated a round-table discussion with experts in the field of population communication. The meeting, which was held at the Population Council office in Cairo, facilitated a sharing of common issues and concerns (such as target audience knowledge and preferences), and coordinating communications activities. In addition, it provided an overall picture of the communication environment and allowed for a better understanding of the information needs of other communication programs. (Minutes of the first meeting of the communications round-table discussion is available in Appendix B). 


\section{FINDINGS}

The information presented on the following pages synthesize the data collected from the agency review survey and the in-depth interviews of this needs assessment. The first section outlines general guidelines and information to dissemination of research. Another part reviews findings on defining target groups, message format, channel mix, and targeted activities. A special section presents an assessment of the dissemination activities of the ANE OR/TA project and audience preference of different channels and other communication activities. Finally, a discussion on networking with other national and international organizations is presented.

\section{Dissemination of Operations Research: General Guidelines}

Operations research is properly defined as a process of conducting programmatic research that involves mangers and policy makers in the design, implementation, dissemination and of the research. In some cases it is referred to as a management tool to provide information from the field that is not otherwise available to policy makers or to program managers. The communication of findings is therefore, a critical activity.

In order to be effective, dissemination activities must address the right audiences and "talk their language". Forming teams that collaborate not only to conduct research but also to disseminate the findings and ensure utilization is one of the vital elements of the dissemination process as one respondents mentioned. When disseminating the results of any study, the communication objectives of planned activities should be clear to better direct the activities. A corollary of the needs assessments was sharing information about professional resources for conducting communications tasks. A list of contact persons of translators, editors, computer graphic specialists, local photographers, art designers and printers was compiled.

\section{ANE OR/TA Project Target Groups}

The ANE OR/TA target groups were analyzed on three levels: local, regional and international. The local level includes NGOs, government officials at the Ministry of Health and Population, Ministry of Social Affairs, the National Population Council as well as other government offices. Regional organizations include syndicates and NGOs, (eg. IPPF regional office for the Arab World). On the international level, bilateral donors, United Nations organizations as well as international NGOs were identified in Cairo.

Two procedures were adopted to refine the understanding of the ANE OR/TA project target groups in Egypt. The first one is to follow a more systematic approach to reach the government 
bodies and NGOs. The second is to explore contacts within the media, women groups and syndicates as new groups that were not considered. In order to sharpen the definition of the ANE OR/TA target groups each of these general categories were investigated horizontally and vertically.

A horizontal investigation means that the different sub-groups within each category, were identified. For example, on the local level, it is vital to involve officials at the governorate level in addition to those at the central offices in Cairo. On the international level, research organizations, cooperating agencies and donors should be better addressed to inform them of the development and the outcomes of the research conducted by ANE OR/TA Project. Organizing special donor meetings, for example, at the interim and final stages of research could be another way to disseminate and utilize research. In all cases, the dissemination program should try to capture as many sub-groups as possible within each of the ANE OR/TA project categories. This could be achieved by reviewing the organizational directories or by mailing a bio-data information sheet to be followed up by phone.

A vertical investigation is another approach to identify the missing target groups. In one interview, it was indicated that women groups, should be more engaged in dissemination of research. NGOs working on the community level should also be involved to ensure a wider diffusion of information. Other groups that have not been approached before, such as the medical syndicates, should receive more attention.

Media are another category that should be addressed systematically to disseminate relevant research information especially those results which are of public concern. The selection of the messages, their content, the identification of the media professionals to cooperate with and the type of medium should be well studied. In most of the interviews a great interest was expressed in using this source of public information as one way of creating public awareness. This cooperation will be most effective if it is linked to the Information, Education and Communication Center (IE\&C Center) of the State Information Service. Some of the issues thought to be relevant for media discussions as mentioned by the interviewees are:

$\checkmark$ Women and reproductive health issues,

$\checkmark$ Maternal and child health care,

$\checkmark$ Nutrition,

$\checkmark$ Male responsibility in family planning and reproductive health,

$\checkmark$ Women's autonomy,

$\checkmark$ Combating rumors, especially regarding newly introduced methods.

In many ways, media cooperation should include raising awareness of media professionals and introducing them to complex and diversified issues, mentioned above. This will facilitate reporting and will minimize misconceptions about these subject matters. During the ICPD, though, some journalists were actively involved in covering the conference, many reports focused on single issues (like abortion), with a lot of sensationalism and subjective arguments. Some of the survey 
respondents have traced this to their lack of scientific information and lack of knowledge of specialized sources that could provide such information.

One way to initiate more cooperation with media is to hold a small scale meetings with reporters of major newspapers such as (Al Ahram and Al Akhbar representing the two major daily newspaper in Egypt) in addition to women magazines like (Nesf El Donia, and Hawa) to discuss current issues and research findings. Organizing similar meetings as new research projects are completed will open more channels of communications.

\section{ANE OR/TA Project Audience Information Needs and Message Format}

Every target group uses the findings of operations research differently based on its interests and needs. In addressing program managers and policy makers, for example, it was indicated that the focus should be on the findings and the recommendations related to policy implications. These findings should also be laid out in a simple format, easy and feasible to implement. It was mentioned that recommendations in particular should be directly relevant to on-going programs.

Policy makers think that the message of operations research should clarify the major outcomes in every research while highlighting how the research has contributed to the improvement of the overall program. Some of their interest areas were mentioned to be quality of care, training, cost and sustainability. For them, brief summaries, preferably in Arabic, could be an effective tool for dissemination as opposed to lengthy final reports. Special briefing sessions were also recommended to allow for more feedback.

Program managers, on the other hand, need the information generated by operations research for project design, setting program objectives, modifying project implementation, improving standards of services and upgrading providers' skills. Service providers have similar information needs but with more focus on issues related to clinical practices, counseling and client-provider relationship. Researchers sampled in the needs assessment expressed their need to learn more about methodological issues as sampling techniques, study designs..etc.

The majority of respondents indicated that the ANE OR/TA Project materials should continue to emphasis information concerning problem identification, methodology, findings, discussions and recommendations. It was mentioned that messages communicating findings of operations research should be brief, concise, clear in analysis and presentation, and has strong visual elements. Whenever possible, providing the results of research in Arabic was believed to be an important way of conveying information. It is worth mentioning that the majority of interviewees mentioned that they share findings of operations research with other professional colleagues in other fields. This implies an expansion in the reach of the operations research messages to many other groups.

\section{Channel Mix in Disseminating Findings of ANE OR/TA Project Research}


The ANE OR/TA Project Dissemination Strategy, classified operations research channels into the following three categories: 1) Interpersonal channels, which include seminars, workshops, conferences, and special briefings; 2) Print channels, such as final reports, summary reports, information and media kits as well as other print tools like using quotations of officials regarding their opinion on a research study, and producing a poster highlighting significant findings in a graphical format; 3) Electronic media, including email utilizing local televisions programs.

The needs assessment indicated that channels fulfilling the audience information needs are mostly research summaries, brief charts, final reports and seminars. Summaries have the advantage of giving the messages in a comprehensive but brief form. Thus they were reported to be more effective for policy makers. Final reports were found useful as a repository reference for detailed information. Program managers reported that final reports are necessity that can not be substituted by summaries. One program manager said "Final reports are extremely important. They are my reference to every research, though I may not read the all the reports, I often consult them." Other types of fact sheets and condensed summaries were indicated to be successful in many ways.

For the two groups, policy makers and service providers, seminars provide an opportunity for discussion and exchange of ideas with other colleagues in the field. Small group meetings were suggested to be a good technique for key program managers to seek opportunities of utilization. Other service providers mentioned that holding local seminars at the governorates will be an effective way to inform senior clinic managers, senior physicians and other service providers about the research. A researcher indicated that publishing a booklet summarizing the methodological experience of operations research will be a useful guide, in the same manner as the "Family Planning Handbook for Operations Research".

Electronic medium, as Email, was also considered to be effective in communicating operations research findings. However, some Email users said that this may be more applicable to US based audiences. Others indicated that they may not be interested to read information messages they receive, especially if their computers are loaded with similar messages everyday.

\section{Dissemination Activities}

Dissemination activities should be tailored to effectively communicate the research findings. Relevant findings to target groups ought to be well addressed and communicated to every group. Audiences should know how the research will improve their programs, and how it can lead to upgrading their services. Failing to do so will result in losing people's interest in the study and, hence, will reduce the possibility that the findings will be used.

The following steps were identified by the respondents to describe the dissemination process:

Create a clear plan for the dissemination of the research under-study, 
- Conduct a seminar, workshop and / or small group meeting at the start of the research and upon the release of the preliminary findings,

Prepare special summaries announcing the beginning of the research,

- Issue an interim report upon availability of preliminary findings,

When possible, keep photographs that document the research process at its different stages.

$\checkmark$ Issue the final report upon completion of the study,

- Issue Arabic and English summary reports,

- Organize an end of project seminar to disseminate the final findings,

- Prepare special briefing kits and information sheets for different occasions,

Distribute summary reports to concerned target groups,

$\checkmark$ Synthesize the research findings to be used for training and other purposes,

$\checkmark$ Contact the media when the research topic is of public concern.

However, there are some problems that usually impede many of these activities. One is unavailability of good mailing lists that are clearly classified. Creating the right classifications of categories on the lists remains the main problem for many organizations.

Evaluation of communications activities is another critical element that could be approached in different ways. Some of the evaluation methods mentioned during the agency review survey included tracking received requests for publications while distinguishing the institutions or individuals requesting these publications, conducting an on site evaluation for major events as conferences and workshops, soliciting readers' feedback and developing distribution plans for materials and tracking how it was implemented.

\section{Assessment of the Dissemination Program of ANE OR/TA Project}

The ANE OR/TA dissemination program was considered to be successful in communicating operations research findings. However, there is more to be done. For example, many respondents thought that there is a need to further publicize the OR messages. In other words, a research project should not be considered completed as soon as a final report is released. Findings should be continually presented to different groups at various occasions.

In one interview it was suggested that dissemination seminars should be announced early enough to provide the chance to attend such an event. Also, reports and summaries should be available along with the invitations to allow for a productive discussion during the seminars. 
When respondents were asked to list some of the communications channels used to disseminate results of the ANE OR/TA Project research, the majority were able to name two or three channels on average. These were mostly final reports, final seminars and research summaries. Though, the Alternatives newsletter was not well recognized, in the cases when it was mentioned it was considered a useful device. It was also perceived as an interesting medium to learn about research news and other regional activities. Yet, some respondents suggested that giving a theme to every issue and presenting the newsletter around that theme may increase its readability. Others indicated that the format is one of the important elements that need to be reconsidered to be as attractive as the research summaries package, for example. In general, the most successful communication channel of the ANE OR/TA Project were mentioned to be the final reports and research summaries.

A scale of one to five was used to rate the content of the dissemination materials (one indicated strongly disapprove and five strongly approve). The content of the ANE OR/TA project materials were perceived to be very clear, consistent, easy to comprehend, acceptable and to some extent useful. However, the timelineness of the message presentation was at the lower side of the scale.

In general it was mentioned that the strongest elements of the dissemination program are the availability of materials, clarity of the messages, and the organization of final seminars. The elements that still need more efforts are the follow up on the utilization of findings, stronger coordination with other agencies, disseminating the messages in a more timely manner, especially before the studies' final seminars.

\section{Networking with National and International Organizations: Communications Round-table Discussion}

As part of this needs assessment, the communications officer of the ANE OR/TA project convened a round-table discussion attended by 12 communications specialists of different organizations at the Population Council office in Cairo, last January 16, 1996. The objectives of the meeting were to identify opportunities for cooperation with other organizations in dissemination of research, learn about the experiences and the lessons learned. The theme of the discussion was "Defining audience information needs in dissemination of research". The two major outcomes of this meeting were learning about the different programs of the attendants and their communications and dissemination capacity. Second, some of the common audiences' information needs were defined for further discussion and for seeking means of collaboration.

The attendants agreed to make this group a working body that will meet quarterly to discuss communications activities. A scope of work will be discussed in the next group meeting set for April 10, 1996. It was agreed that the major areas of coordination that concern this group are dissemination and utilization of research, training (where communication is concerned), and working with NGOs and the media. It was suggested that some of the activities to fulfill the above areas could include: 
$\checkmark$ Mapping of research in related areas. (A starting point will be that each attendant in the next meeting will present a summary of his/her research program and its dissemination plan)

$\checkmark$ Exchange of materials related to research,

$\checkmark$ Exchange of experience on targeting special audience groups,

$\checkmark$ Exchange of information on various resources for facilitating communication activities.

This round-table discussion served as a tool to establish links with national and international organizations working in Egypt. The group activities will provide an opportunity for more systematic cooperation and a wider dissemination of results, especially with the ANE OR/TA Project target groups.

\section{LESSONS LEARNED FROM THE NEEDS ASSESSMENT AND FOLLOW UP ACTIVITIES}

The following points summarizes the lessons learned from this needs assessment and the follow up activities:

- There is a general satisfaction with the dissemination activities of the ANE OR/TA Project. Yet there are areas that require more work. Follow up activities after research studies are completed should be strengthened. Repackaging research findings for use at different occasions is another way of spreading the messages and enhancing the utilization of findings.

- Networking and coordination of activities in the area of dissemination and utilization of research is an important professional activity that the ANE OR/TA project can stimulate and nurture.

- Policy makers and program managers tend to prefer learning about the research findings through targeted small group meeting and/or dissemination seminars in addition to brief summaries. Providing complete final reports as well as other types of summaries, should be done sometimes before final dissemination seminars to allow for a more productive discussion.

- Exploring new groups to disseminate the findings of research (eg. the medical syndicates and women's groups should be considered.

- Using electronic channels, as Email, should be carefully planned for, though, this medium maybe more suitable for US based audiences than those in Egypt.

- "Alternatives" format and themes will become more responsive to our audiences' needs.

- The planned ANE OR/TA Project publication, "Lessons Learned Booklet" should be an opportunity to communicate the major outcomes of the ANE OR/TA Project over the past five years, utilization of research and its impact on policy and / or other programs. This booklet should also highlight the experience of the project in creating this impact.

- A publications on synthesizing the experience of the ANE OR/TA Project methodology 
designs should be considered. This publication will be mainly addressed to researchers and could be distributed locally, regionally and internationally.

- The evaluation of communications activities should be strengthened. Tools such as the tracking of requests for publications both institutional and individual and readers' feedback need to be used more frequently. Other activities like conducting small scale survey to follow up dissemination and utilization activities are also desirable.

- A file of resources for conducting communications activities, eg. editing, translation, art design...etc. is available.

\section{CONCLUSION}

This small scale study helped to widen the knowledge of the ANE OR/TA Project target groups, messages and channels. It also provided an overall assessment of the project dissemination program, and the audience feedback to implemented activities. In many ways, this needs assessment strengthened the basis for implementing forthcoming dissemination activities. The Evaluation techniques used by other organizations were useful to learn about. This exercise has also produced many important lessons that will not only be useful to the dissemination program of the ANE OR/TA project, but also to other OR Projects and similar programs in other organizations both within Egypt and in other countries. 


\section{REFERENCES}

Bertrand Jane T, Robert J Magnani and James C. Knowles. Handbook of Indicators for Family Planning Program Evaluation. The Evaluation Project, 1994.

Creswell, John W. Research Design: Qualitative and Quantitative Approaches. London: Sage Publications, 1994.

Helitzer-Allen, Deborah L. and Hubert A. Allen, Jr. The Manual for Targeted Intervention Research on Sexually Transmitted Illnesses with Community Members. Family Health International, 1994.

Katz, Karen, Karen Hardee and Michele T. Villinski. Quality of Care in Family Planning: A Catalog of Assessment and Improvement Tools. Family Health International, 1993.

Maibach, Edward and Roxanne Louiselle Parrott (Eds.). Designing Health Messages: Approaches from Communications Theory and Public Health Practice. London: Sage Publications, 1995.

. Project Design for Program Managers. The Center for Development and

Population Activities (CEDPA), 1994.

Rogers, Everett $\mathrm{M}$ and Rekha Agarwala-Rogers. Evaluation Research on Family Planning Communications. UNESCO, 1974.

Starrs Ann M, and Rahna R. Rizzuto. Getting the Message Out: Designing an Information Campaign on Women's Health. Family Care International, 1995.

Taylor Carol, Fitz Gibbon and Lynn Lyons Morris. How to Design a Program Evaluation. London: Sage Publications, 1987.

Wallack, Lawrence, Lori Dorfman, David Jernigan and Makani Themba. Media Advocacy and Public Health: Power for Prevention. Newbury Park: Sage Publications, 1993. 


\section{APPENDIX A}

Agencies contacted for review of their communications program:

1. Demographic Health Survey (DHS)

2. UNICEF

\section{List of Interviewees:}

1. Dr. Magdy Khaled

Training Specialist

Population Project Consortium (PPC)

2. Dr. Ayman Abdel Mohsen

Director

Private Sector Initiative Project (PSI)

3. Dr. Hassan El Gebally

Director

System Development Project, Ministry of Health (SDP Project)

4. Ms. Amani Selim,

Project Management Specialist

United States Agency For International Development (USAID/Cairo)

5. Ms. Jocelyn DeJong

Reproductive Health Officer

Ford Foundation

6. Dr. Fatma El Zanaty

Associate Professor

Cairo University and Technical Director of the EDHS 


\title{
APPENDIX B \\ Communication Round Table Discussion on Dissemination \& Communication of Research
}

\author{
Minutes of Discussion
}

\section{Attendants:}

Mr. Ron Hess

Dr. Samir El Alfy

Dr. Salah Eldin Mohammed

Ms. Nagwa Farag

Ms. Dina Zahran

Ms. Sahar Hegazi
Ms. Sawsan El Bakly

Ms. Mary Halim Basta

Dr. Hassan El Gebaly

Dr. Kamel Fayoumi

Mr. Dina Osman

Dr. Nahla Abdel Tawab

(for full information, please refer to attached grid of list of participants)

\section{Absents:}

Mr. Fathi Osman (Director, IE\&C Office/SIS)

Dr. Mohammed Edrees (Director, CSI Project)

Mr. Gamal El Nahas (Director, IE\&C Project/NPC)

Dr. Samir Khamis (National Consultant, IE\&C Project/NPC)

Sahar Hegazi (The Population Council) started the discussion reviewing the objectives of the meeting which include sharing the experience of communication and dissemination of research. She identified some of the problems that hinder dissemination as for example the lack of coordination among concerned groups.

Dr. Samir El Alfy (IE\&C Center) and Dr. Karem Fayoumy (Regional Center for Training) mentioned that there are many areas, where coordination of communication activities is highly needed, in addition to dissemination. For example, rumors about some contraceptives as the injectable is considered a major obstacle in the program development. In spite of the fact that nurses and physicians were trained at the Regional Center for Training (RCT) on how to combat these rumors, it was found out that in EI Wadi El Gadid governorate, for example, rumors come from the physicians themselves.

Ms. Sawsan El Bakly and Dr. Hassan El Gebaly (System Development Project) explained the need to better coordinate interpersonal communication activities. Educational courses could be for 2 or 3 weeks, since physicians have no proper communication skills and there is a great communication gap between providers 
and clients especially where family planning and reproductive health are concerned. Research related messages could be then used in these training sessions.

Mary Halim (Research Management Unit) presented the new Database project of RMU and explained the methodology of data collection and the use of this data. She also distributed a summary grid of RMU research studies.

Ron Hess (Population Project Consortium) gave a brief presentation on some of the communication studies conducted with IE\&C center and SDP Project (a handout was distributed).

Nagwa Farag (UNICEF) mentioned the need for having one pool for referring to communication and population studies, which will require constant update. She briefed the group on a Qualitative / Quantitative study on Child Media Habits and on the UNICEF most recent project on Healthy Mother Healthy Child. She also explained some of the UNICEF communication and dissemination activities in training the media professionals, briefing parliamentaries and working with NGOs.

Sahar Hegazi presented a quick overview on the studies conducted by the Asia and Near East Operations Research and Technical Assistance Project (ANE OR/TA Project) concerning family planning and reproductive health. Following, Nahla Abdel Tawab (The Population Council) briefed the group on the forthcoming counseling study of husbands and wives.

Dina Osman (Egyptian Family Planning Association) reviewed some of the Egyptian Family Planning Association activities especially related to IE\&C. However, she mentioned that their main communication problem is the lack of public awareness of clinics and services provided by EFPA.

It was mentioned that among the needy groups for communication assistance is the NGO sector who should learn the different types of communication activities and doing community outreach.

\section{The Following was agreed upon:}

- Attendants agreed to make this group a continuous working body called "Communication Coordinating Group".

The group should meet quarterly to discuss specific activities that could be coordinated.

Sahar Hegazi and Nagwa Farag will draft some form of a specific scope of work for the group to be discussed next time. Yet, it was generally agreed that the major areas of coordination are:

- Dissemination and Utilization of research 
- Training (where communication is concerned)

- Working with NGOs (where communication is concerned)

It was suggested that some of the activities to fulfill the above areas could include:

- $\quad$ Mapping of research in related areas. (A starting point will be that each attendant of the next meeting will present the group with a summary of his/her research program and its dissemination plan)

- $\quad$ Exchange of materials and resources related to research,

- $\quad$ Exchange of experience on targeting special audience groups,

- Exchange of information on various resources for facilitating communication activities.

Next meeting was set for April 10, 1996 between 12:00 to 3:00 pm. at the Population Council office.

The Agenda for next meeting will be tentatively:

- $\quad$ Review of meeting agenda,

- Review of the group scope of work,

- $\quad$ Presentation by each organization on their research program, and discussion of related dissemination activities possible for coordination.

- Each presenter should provide the following information:

- Title of the study

- Date

- Principle investigator \& implementing Agency

- Project Status (on-going - completed)

- Brief description of each study objectives, methodology and main findings

- Your dissemination and utilization plans

- Information should be forwarded to:

Ron Hess

IE\&C Specialist

Population Council Consortium of Egypt

1 Aisha El Taymouria St., 7th Floor

Garden City, Cairo, Egypt

Tel: $3558150 / 8151 / 8152$

Fax: 3559844

Ron has volunteered to put all the information in a common shape ready for distribution and discussion during the next meeting. ALL INFORMATION SHOULD BE SENT TO RON BY FEB. 15 


\section{List of Participants of the Communications Round Table Discussion The Population Council -- January 16, 1996}

\begin{tabular}{|c|c|c|c|}
\hline Name & Title & Organization & Address -- Tel. -- Fax \\
\hline 1. Mr. Ron Hess & Resident Consultant & $\begin{array}{l}\text { Population Project } \\
\text { Consortium (PPC) }\end{array}$ & $\begin{array}{l}1 \text { Aisha El Taimouria St. } \\
\text { T: } 3558150\end{array}$ \\
\hline 2. Dr. Samir El Alfy & SIS/IEC Consultant & $\begin{array}{l}\text { IE\&C Center - System } \\
\text { Development Project } \\
\text { (SDP) }\end{array}$ & $\begin{array}{l}3 \text { Tahrir Sq. } \\
\text { T: } 3556688\end{array}$ \\
\hline $\begin{array}{l}\text { 3. Dr. Salah Eldin } \\
\text { Mohammed }\end{array}$ & IEC Officer at SDP Project & $\begin{array}{l}\text { System Development } \\
\text { Project (SDP) - Ministry of } \\
\text { Health (MOH) }\end{array}$ & $\begin{array}{l}3 \text { Maglis El Shaab St., Kasr El } \\
\text { Eini } \\
\text { T: } 3554937\end{array}$ \\
\hline 4. Ms. Sawsan El Bakly & IEC Consultant to SDP/MOH & $\begin{array}{l}\text { System Development } \\
\text { Project (SDP) - Ministry of } \\
\text { Health (MOH) }\end{array}$ & $\begin{array}{l}3 \text { Maglis El Shaab St., Kasr EI } \\
\text { Eini } \\
\text { T: } 3554937\end{array}$ \\
\hline 5. Ms. Mary Halim & NPC/RMU Dissemination & $\begin{array}{l}\text { National Population } \\
\text { Council - Research } \\
\text { Management Unit (RMU) }\end{array}$ & $\begin{array}{l}\text { Kornishe El Nil, Maadi } \\
\text { T: } 3638551\end{array}$ \\
\hline 6. Dr. Hassan El Gebaly & Executive Director & $\begin{array}{l}\text { System Development } \\
\text { Project (SDP) }\end{array}$ & $\begin{array}{l}3 \text { Maglis El Shaab St., Kasr El } \\
\text { Eini } \\
\text { T: } 3554937 \text { F: } 3557009\end{array}$ \\
\hline 7. Ms. Dina Osman & IEC Officer & $\begin{array}{l}\text { Egyptian Family Planning } \\
\text { Association (EFPA) }\end{array}$ & $\begin{array}{l}6 \text { Gizerat El Arab } \\
\text { T: } 3607329 \quad \text { F: } 3607328\end{array}$ \\
\hline
\end{tabular}




\begin{tabular}{||l|l|l|l||}
\hline 8. Ms. Nagwa Farag & $\begin{array}{l}\text { Information / Communication } \\
\text { Officer }\end{array}$ & UNICEF & $\begin{array}{l}8 \text { \& 11 Adnan Omar Sidky St. } \\
\text { Dokki } \\
\text { T: } 3372327\end{array}$ \\
\hline 9. Ms. Dina Zahran & Communication Officer & $\begin{array}{l}\text { Regional Center for } \\
\text { Training (RCT) }\end{array}$ & $\begin{array}{l}\text { Aim Shams Maternity University } \\
\text { T: } 2831956\end{array}$ \\
\hline 10. Dr. Karem Fauomy & Head of Training Unit & $\begin{array}{l}\text { Regional Center for } \\
\text { Training (RCT) }\end{array}$ & $\begin{array}{l}\text { Aim Shams Maternity Hospital } \\
\text { T: } 2831956\end{array}$ \\
\hline 11. Sahar Hegazi & Communications Officer & The Population Council & $\begin{array}{l}\text { 6A Giza St. (Bahie Eldin } \\
\text { Barakat), Giza } \\
\text { T: } 570133 / 5738277 \\
\text { F: } 5701804\end{array}$ \\
\hline 12. Nahla Abdel Tawab & $\begin{array}{l}\text { Operations Research Country } \\
\text { Fellow }\end{array}$ & The Population Council & $\begin{array}{l}6 \mathrm{6A} \text { Giza St. (Bahie Eldin } \\
\text { Barakat), Giza } \\
\text { T: } 570133 / 5738277 \\
\text { F: } 5701804\end{array}$ \\
\hline
\end{tabular}

